\title{
The Importance of Homology for Biology and Philosophy
}

Ingo Brigandt $^{1}$ and Paul E. Griffiths ${ }^{2}$

Homology is one of the most important concepts in biology (de Beer 1971; Donoghue 1992). Having been introduced in pre-Darwinian comparative biology, it continues to be fundamental to taxonomy, phylogeny, and evolutionary biology. In recent times it has come to play an important role in molecular and developmental biology. In addition to figuring prominently in biological practice, the notion of homology is the subject of extensive theoretical reflection among biologists (Bock and Cardew 1999; Hall 1994; Wagner 2001b). Curiously though, homology has been discussed only sparsely by philosophers. ${ }^{3}$ The contributions to this special issue attempt to highlight the importance of homology for philosophy as well as biology. Homology is germane to such philosophical issues as the individuation of biological natural kinds, and the patterns of inductive reasoning in the life sciences. Given the possibility of individuating cognitive kinds and mental phenomena in terms of homology (rather than their evolutionary function), the idea of homology has implications for the philosophy of mind and cognitive science, implications that are explored in the contributions of Marc Ereshefsky and Mohan Matthen.

While species have been extensively discussed by philosophers and have served as the prime examples of biological natural kinds, homology is an equally important notion of natural kindhood in the biological sciences (Brigandt 2002, in press; Rieppel 2006; Wagner 1996,

${ }^{1}$ Department of Philosophy, University of Alberta, 4-115 Humanities Centre, Edmonton AB T6G 2E5, Canada, email: brigandt@ualberta.ca

${ }^{2}$ School of Philosophical and Historical Inquiry, University of Sydney, Quadrangle A14, Sydney, NSW 2006, Australia and ERSC Centre for Genomics in Society, Byrne House, University of Exeter, Exeter, Devon EX4 4RJ, UK email: paul.griffiths@usyd.edu.au

${ }^{3}$ These discussions include Amundson (2005), Amundson and Lauder (1994), Brandon (1999), Brigandt (2002, 2003), Griffiths (1994, 1996, 2006), Matthen (1998, 2000), and Sober (1999). 
2001a). Biologists partition an organism into homologues which are presumed to represent natural units of biological organization because they can be reidentified in other organisms and other species (Griffiths, this issue). A homologous character shares many biological properties in the different organisms in which it occurs, and there is a causal basis for this sharing of properties (common ancestry and shared developmental mechanisms). These two features, a cluster of properties and a causal basis for the co-occurrence of those properties, are the two hallmarks of natural kinds (Boyd 1991; Hacking 1991; Wilson et al., in press). In the course of evolution, a character typically undergoes modification, so that homologues are units of phenotypic transformation (Brigandt, this issue). Thus, homologues are important morphological-developmental, taxonomic, and evolutionary units.

The notion of homology has a long and rich history. It was developed in the first half of the $19^{\text {th }}$ century in comparative morphology and embryology (Le Guyader 2004; Owen 1848). Pre-Darwinian biologists already possessed fairly reliable criteria of homology, and the homologies between different species which they identified provided critical evidence for the theory of common ancestry (Darwin 1859, Ch. 13; Amundson 2005; Remane 1956; Russell 1916). Once homology had been interpreted as a reflection of shared ancestry, it proved to be the central tool for phylogenetic studies, such as $19^{\text {th }}$ century evolutionary morphology (Gegenbaur 1870; Haeckel 1866; Lankester 1870; Nyhart 1995). In the second half of the $20^{\text {th }}$ century, modern phylogenetic systematics (cladistics) introduced more reliable methods for distinguishing homologies from homoplasies (similarities not due to common ancestry), so as to permit the construction of well-supported phylogenies (Hennig 1966).

Over the past few decades there has been an intensification of interest in the concept of homology. Its scope of application has increased and new theoretical interpretations of homology have been proposed. In addition to traditional morphological characters, processes and functions can be homologised (Amundson and Lauder 1994; Gilbert and Bolker 2001; Gilbert et al. 1996; Lauder 1994), and behavioural patterns and cognitive features are increasingly recognized as homologous across species (see Ereshefsky, this issue; Matthen, this issue). Following the rise of molecular biology, genes and proteins came to be homologized, leading to the field of molecular evolution and the practice of using molecular 
data to arrive at and revise phylogenetic trees (Hillis 1994). Alan Love (this issue) discusses how molecular developmental biologists conceive of genetic and developmental functions as homologies across species. Not only can these many different kinds of characters be homologous, but it has been discovered that homology on one level of organismal organization can be dissociated from and must not be confused with homology on another level. That is to say, a structure that is homologous across species can develop based on nonhomologous genes and/or developmental processes, and vice-versa (Abouheif 1997; Bolker and Raff 1996; Brigandt 2006, this issue; Ereshefsky, this issue; Hall 1995; Müller and Wagner 1996). The new and thriving field of evolutionary developmental biology attempts to account for the developmental basis of evolutionary change, evolvability, and the origin of evolutionary novelties and body plans. It has produced a range of new, developmental approaches to homology and has made homology a major focus of theoretical reflection and discussion (Brigandt 2002, 2003; Cracraft 2005; de Beer 1971; Donoghue 1992; Gilbert and Bolker 2001; Gilbert et al. 1996; Griffiths, this issue; Laubichler 2000; Love and Raff 2006; Müller 2003; Müller and Newman 1999; Rieppel 2006; Wagner 1989a, 1989b, 1994, 1996, 2001a, 2007; Wagner and Stadler 2003).

Biological discussions of homology are often conducted in terms of competing homology 'concepts'. This probably reflects the older tradition of discussing the nature of species in terms of competing 'species concepts'. In both these debates 'concept' is used to mean something like 'theoretical account' and does not carry the implication that biologists with different concepts are not thinking about the same thing. But even when it is made clear that 'different concepts' is to be interpreted in this fairly mundane way, we do not think it is helpful to treat disputes about homology as disputes about which concept (= definition) to adopt. So-called definitions of homology typically embody substantive commitments about how evolution and development work, and/or embody a particular methodological approach to the study of homology. Even when biologists do seem to be talking past one another as a consequence of adopting different 'definitions' of homology, those definitions are the reflection, rather than the cause, of differences in the questions they think are important and the methods they use to approach those questions (Brigandt 2002, 2003). Hence, philosophical efforts to analyse these debates should not focus on the definitions themselves, 
but on the substantive claims about living systems which are reflected in those definitions and the methodological consequences of using those definitions. Using such an approach, both Ingo Brigandt (this issue) and Paul Griffiths (this issue), argue that the dominant contemporary approaches to homology are strongly complementary and that they work together to explain evolution (Brigandt) and the identity of the parts of organisms (Griffiths). In what follows we will refrain from talking of 'homology concepts'. Since any definitional differences are closely linked to differences in scientific practice, it makes more sense to talk of different 'approaches' to homology.

Perhaps the best known approach to homology is the 'taxic' approach associated with mainstream work in contemporary systematics. Forty years of philosophical interest in the 'species problem' means that the taxic approach of homology is also the best known amongst philosophers (see e.g. Ereshefsky 1991, 2001; Hull 1970, 1997; Sober 1988; Wilson 1999). The taxic approach uses points of resemblances between organisms (shared character states) to diagnose their evolutionary relationships (Brigandt 2002, 2003; Donoghue 1992). These points of resemblance may reflect common ancestry (homology) or reflect other causes such as convergent evolution and mere coincidence (homoplasy). The taxic approach to homology, and its role in the reconstruction of evolutionary relationships, is discussed in the papers by Brigandt and Griffiths.

The closely related 'transformational' approach to homology focuses on the different states in which the same character can exist as it is transformed by evolution (Brigandt 2003, this issue; Donoghue 1992). The transformational approach comes closest to the spirit of the nineteenth century research traditions that pioneered the study of homology. Richard Owen's original definition of a homologue as 'The same organ in different animals under every variety of form and function. (Owen 1843: 379), while not explicitly historical, indicates that a homologue is a character (a determinable property in philosophical parlance) rather than a specific character state (a determinate property). A homologue is the same part, such as the vertebrate limb, under every variety of form from shrew to elephant, and every variety of function from burrowing to flying. The transformational approach to homology plays a part in sorting out evolutionary relationships between organisms, but in addition, and unlike the taxic 
approach, it focuses on the sequence of events in the evolution of a lineage. There are also methodological differences between the two approaches. The taxic approach is associated with a holistic approach to diagnosing homology, aiming at the best explanation of the overall pattern of shared character states between organisms. The transformational approach is more localist, focusing on one or a few characters and gathering descriptive and experimental evidence to diagnose their homologies (for examples, see Griffiths, this issue).

A third approach to homology, or rather a family of approaches, has emerged in the last twenty years, in conjunction with the rise of 'evolutionary developmental biology' (evodevo). Evo-devo uses the new techniques of molecular biology, and especially molecular developmental biology, to address questions about the interaction of development and evolution which were once at the heart of the study of evolution but receded into the background with the 'modern synthesis' and its emphasis on population genetics (Brigandt 2006; Love 2001; Love and Raff 2003; Maienschein and Laubichler 2007; Müller and Newman 2003; Wagner 2000). Developmental approaches to homology seek to causally explain the fact that organisms come in repeatable parts (homologues). Parts are repeatable both within organisms and between organisms. Arthropods consist of various numbers of segments, each with a characteristic set of homologous parts, such as paired appendages. The different segments of a single arthropod are homologous with one another, sometimes obviously so, as with the many near-identical segments of a millipede, and sometimes less obviously so, as when detailed investigation reveals that the head of a crustacean is composed of several, fused segments with highly modified appendages. Corresponding parts of arthropod segments are homologous across taxa. The gills of a crab and the wings of a fly are homologues of one another and are both homologues of the appendages used for oxygen exchange in their common ancestor (Averof and Cohen 1997). Developmental approaches to homology focus on the fact that homologies are repeated instances of the same developmental phenomenon. They ask how developmental processes achieve this degree of robustness, and why they remain discrete and identifiable to such an extent when their form and function is transformed by evolution. Thus, unlike taxic and transformational approaches to homology, developmental approaches aim to make a direct contribution to understanding the causal mechanisms by which evolution occurs. For example, Brigandt (this issue) argues that 
understanding homology is a vital part of understanding evolution because homologues are the units of evolvability.

Developmental approaches to homology have transformed one traditional topic of evolutionary thought - evolutionary novelty - and introduced a whole new topic - levels of homology. Both of these topics can be exemplified in the case of arthropod segments. Segmentation is a unifying theme in the structural biology of arthropods, and is the basis of the evolutionary potential revealed by the impressive range of arthropod diversity, from butterflies to giant crabs. But the flexible system which makes possible this diversity is itself a product of evolution - an evolutionary novelty. Recent work on novelty in evolutionary developmental biology identifies 'novelties' with features that have no pre-existing homologue (Müller and Wagner 1991). Modern synthesis biology assumed that novelties evolved gradually via a series of small genetic changes, like all other traits, and were marked as 'novelties' only by their subsequent effect on the course of evolution (Mayr 1960). The new approach to novelty highlights the question of how a developmental system can produce a trait which is not a modification of an existing trait, a question that was pushed into the background by the earlier focus on the fact that novelties allow substantive new functions to be performed. Some evolutionary developmental biologists have proposed a critical role for epigenetic mechanisms and the emergent organization of development in the origins of novelty (Newman and Müller 2000; Müller and Newman 1999, 2003). Love (this issue) explores the application of some of these ideas to the origin of novel functions, or what he terms evolutionary 'innovations'.

Most of the papers in this issue discuss some aspect of the 'levels' of homology. The morphological features that have traditionally been homologized within and between organisms are built by developmental processes, which themselves rest on underlying genetic and epigenetic architectures. Hence it seemed reasonable to assume that homologous traits would be built in the same way, and using the same genes. However, the initial application of the new techniques of molecular developmental biology to diagnose homologies produced some puzzling results. For example, the camera eye of vertebrates and the compound eyes of insects cannot have evolved from a common, ancestral eye and yet some of the critical genetic 
resources used in their construction are the same (Quiring et al. 1994). Similarly, some ancient genetic pathways seem to be shared between arthropod appendages and vertebrate limbs (Shubin et al. 1997). Results like these have led to a consensus that homology at the phenotypic level is potentially decoupled from homology of developmental processes and homology at the level of the genome. Shared developmental pathways or gene expression patterns are important but defeasible evidence for homology. As the leading evolutionary developmental biologist Brian K. Hall has written:

"Both homology and homoplasy can be defined at different levels without making judgments about homology or homoplasy, or lack of homology/homoplasy at other levels. Indeed, to identify the hierarchical level of homology or homoplasy being specified, we should always speak of 'homologous as limbs, homologous as digits, homologous as a developmental process, homologous as a gene network, etc" (Hall 2003: 425).

In his paper in this special issue, Love breaks new ground by applying the idea of levels of homology to homologies of function. While it has been suggested that homologies of function are potentially independent of the homologies of the structures that underpin function (e.g. Lauder 1990), we are not aware of any previous work that distinguishes different levels of functional homology analogous to the levels of morphological homology.

Love builds on recent philosophical work on the notion of biological function to draw a number of critical distinctions that are required if the very idea of homology of function is to make sense. Traditionally, the term function has been associated with the idea of evolutionary analogy. The function of a trait is the purpose for which it was designed by natural selection and hence the feature in virtue of which that trait is an evolutionary analogue of other traits that have been shaped by natural selection for the same end. But there is also a more straightforwardly descriptive sense of 'function', in which the function of a trait is a measurable physical property of the sort studied by functional anatomists (Amundson and Lauder 1994). The function of a trait in this descriptive sense need not be the same as the function for which it was selected, and more importantly, biologists do not need to know the evolutionary purpose of a trait in order to describe its function (Griffiths 2006). Earlier philosophical discussion has focused on a contrast between selected function and descriptive 
senses of function in general. Following Arno Wouters (2003, 2005), Love distinguishes between various descriptive senses of function: the contribution a trait makes to the biological viability of the whole organism, the causal role a trait plays in some larger system of which it is a part, and the 'mere activity' of the trait. The mere activity of a trait is a performance or capacity which can be abstracted from any particular use that may be made of the trait by a containing system. Love argues that a notion of homology of function that coincides with homology of 'activity' plays a central role in comparative genomics and molecular developmental biology.

Ereshefsky and Matthen's papers focus on the implications of 'homology thinking' for the philosophy of mind. Philosophical discussion of the classification of psychological states still bears the imprint of the philosophical school known as 'functionalism' which proposed for primarily metaphysical reasons that mental states are defined by their function (Armstrong 1968; Fodor 1975; Putnam 1967). Functionalists understood 'function' to mean something like the causal contribution made by a part to the overall capacity of an organism to display intelligent behaviour. Some later authors proposed strengthening functional definitions of mental states by stipulating that the functions must be those for which the relevant parts were selected in the evolutionary past (Millikan 1984; Sober 1985). Moreover, for largely independent reasons the dominant school of contemporary Evolutionary Psychology holds that the correct 'anatomy of mind' is a division of the mind into parts each defined by a specific purpose for which they were selected (Barkow et al. 1992). Against this background it is unsurprising that the idea that mental states are to be defined by homology has hardly been explored (but see Griffiths 1997, 2007; Matthen 1998, 2000). The idea that behavioural traits can be homologised was one of the founding doctrines of classical ethology, the first phase in the modern, Darwinian tradition of animal behaviour research. Until recently, however, this aspect of ethology remained quite marginal. In his contribution Ereshefsky describes the methods used by some contemporary ethologists to homologise behaviour and argues that these methods can be applied quite directly to psychological traits. He argues that an evolutionary psychology which attended to the identity of traits as homologues as well as to their identity as analogues would be in a better position to test evolutionary explanations of 
those traits. It would also be in a better position to handle the complex issues raised by the interaction of genetic and other factors in the ontogeny of mind and behaviour.

Matthen's paper applies the idea of homology still more directly to the mind. Using richly developed examples from the science of vision he argues that functional definitions of psychological traits are vague and unsatisfactory unless they are enriched with taxonomic considerations. For the purposes of science, the functions that matter are the specific functions of avian vision or primate vision. These more specific functions, he argues, are themselves the products of a specific evolutionary history and thus best conceived of as homologies.

The papers which make up this Special Issue were initially presented at a meeting of the Philosophy and Developmental Biology Working Group ${ }^{4}$ in Vancouver, Canada in November 2006. Revised versions were presented in sessions organised by Marc Ereshefsky at the July 2007 meeting of the International Society for the History, Philosophy and Social Studies of Biology ${ }^{5}$ in Exeter, UK. Gerd B. Müller, a major contributor to the scientific literature on homology, acted as a commentator and was kind enough to provide his notes to the authors of this introduction. We hope that publishing these papers together will encourage more philosophers of science to turn their attention to this fascinating aspect of biology.

\section{References}

Abouheif, E.: 1997, Developmental Genetics and Homology: A Hierarchical Approach, Trends in Ecology and Evolution 12, 405-408.

Amundson, R.: 2005, The Changing Role of the Embryo in Evolutionary Thought: Roots of Evo-Devo, Cambridge University Press, Cambridge.

Amundson, R. and Lauder, G.: 1994, Function Without Purpose: The Uses of Causal Role Functions in Evolutionary Biology, Biology and Philosophy 9, 443-469.

\footnotetext{
${ }^{4}$ http://www.public.asu.edu/ jrobert6/phildevo.htm

${ }^{5}$ http://www.ishpssb.org/
} 
Armstrong, D.M.: 1968, A Materialist Theory of Mind. Routledge \& Kegan Paul, London.

Averof, M. and S.M. Cohen: 1997, 'Evolutionary origin of insect wings from ancestral gills', Nature 385, 627-630.

Barkow, J.H., L. Cosmides and J. Tooby (eds.): 1992, The Adapted Mind: Evolutionary Psychology and the Generation of Culture. Oxford University Press, Oxford.

Boyd, R.: 1991, 'Realism, anti-foundationalism and the enthusiasm for natural kinds', Philosophical Studies 61, 127-148.

Bock, G.R. and Cardew, G. (eds.): 1999, Homology, John Wiley \& Sons, Chicester.

Bolker, J.A. and Raff, R.A.: 1996, Developmental Genetics and Traditional Homology, BioEssays 18, 489-494.

Brandon, R.N.: 1999, The Units of Selection Revisited: The Modules of Selection. Biology and Philosophy 14, 167-180.

Brigandt, I.: 2002, Homology and the Origin of Correspondence, Biology and Philosophy 17, $389-407$.

Brigandt, I.: 2003, Homology in Comparative, Molecular, and Evolutionary Developmental Biology: The Radiation of a Concept, Journal of Experimental Zoology (Molecular and Developmental Evolution) 299B, 9-17.

Brigandt, I.: 2006, Homology and Heterochrony: The Evolutionary Embryologist Gavin Rylands de Beer (1899-1972), Journal of Experimental Zoology (Molecular and Developmental Evolution) 306B, 317-328.

Brigandt, I.: in press, Natural Kinds in Evolution and Systematics: Metaphysical and Epistemological Considerations, Acta Biotheoretica.

Cracraft, J.: 2005, Phylogeny and Evo-Devo: Characters, Homology, and the Historical Analysis of the Evolution of Development, Zoology 108, 345-356.

Darwin, C.: 1859, On the Origin of Species by Means of Natural Selection, Or the Preservation of the Favoured Races in the Struggle for Life, John Murray, London. de Beer, G.R.: 1971, Homology, An Unsolved Problem, Oxford University Press, Glasgow. 
Donoghue, M.J.: 1992, Homology, in E.F. Keller and E.A. Lloyd (eds.), Keywords in Evolutionary Biology, Harvard University Press, Cambridge, MA, pp. 170-179.

Ereshefsky, M. (ed.) 1991, The Units of Evolution: Essays on the Nature of Species. Bradford Books/MIT Press, Cambridge, MA.

Ereshefsky, M.: 2001, The Poverty of the Linnaean Hierarchy: A Philosophical Study of Biological Taxonomy. Cambridge University Press, Cambridge.

Fodor, J.A.: 1975, The Language of Thought. T.Y. Crowell Co. Inc.

Gegenbaur, C.: 1870, Grundzüge der vergleichenden Anatomie, 2nd edition, Wilhelm Engelmann, Leipzig.

Gilbert, S.F. and Bolker, J.A.: 2001, Homologies of Process and Modular Elements of Embryonic Construction, Journal of Experimental Zoology (Molecular and Developmental Evolution) 291, 1-12.

Gilbert, S.F., Opitz, J.M. and Raff, R.A.: 1996, Resynthesizing Evolutionary and Developmental Biology, Developmental Biology 173, 357-372.

Griffiths, P.E.: 1994, Cladistic explanation and functional explanation, Philosophy of Science 61, 206-227.

Griffiths, P.E.: 1996, The Historical Turn in the Study of Adaptation, British Journal for the Philosophy of Science 47, 511-532.

Griffiths, P.E.: 1997, What Emotions Really Are: The Problem of Psychological Categories. Conceptual Foundations of Science. University of Chicago Press, Chicago.

Griffiths, P.E.: 2006, Function, Homology, and Character Individuation, Philosophy of Science 73, 1-25.

Griffiths, P.E.: 2007, “Evo-Devo Meets the Mind: Towards a Developmental Evolutionary Psychology", in R. Sansom and R. Brandon (eds.), Integrating Evolution and Development: From Theory to Practice. MIT Press, Cambridge, MA, pp. 195-226.

Hacking, I.: 1991, 'A Tradition of Natural Kinds', Philosophical Studies 61, 109-126.

Haeckel, E.: 1866, Generelle Morphologie der Organismen: Allgemeine Grundzüge der organischen Formen-Wissenschaft, mechanisch begründet durch die von Charles Darwin 
reformirte Descendenz-Theorie, Georg Reimer, Jena.

Hall, B.K. (ed.): 1994, Homology: The Hierarchical Basis of Comparative Biology, Academic Press, San Diego.

Hall, B.K.: 1995, Homology and Embryonic Development, in M.K. Hecht, R.J. MacIntyre and M.T. Clegg (eds.), Evolutionary Biology, Vol. 28, Plenum Press, New York, pp. 1-37.

Hall, B.K.: 2003, 'Descent with modification: the unity underlying homology and homoplasy as seen through an analysis of development and evolution', Biological Review 78, 409433.

Hall, B.K. and Olsson, W.M. (eds.): 2003, Keywords and Concepts in Evolutionary Developmental Biology. Harvard University Press, Cambridge, MA.

Hennig, W.: 1966, Phylogenetic Systematics, Urbana: University of Illinois Press.

Hillis, D.M.: 1994, Homology in Molecular Biology, in B.K. Hall (ed.), Homology: The Hierarchical Basis of Comparative Biology, Academic Press, San Diego, pp. 339-368.

Hull, D.L.: 1970, 'Contemporary systematic philosophies', Annual Review of Ecology \& Systematics 1, 19-54.

Hull, D.L.: 1997, 'The ideal species concept - and why we can't get it', in M.F. Claridge, H.A. Dawah and M.R. Wilson (eds.), Species: The Units of Biodiversity. Chapman Hall, New York, pp. 358-379.

Lankester, E.R.: 1870, On the Use of the Term Homology in Modern Zoology, and the Distinction between Homogenetic and Homoplastic Agreements, The Annals and Magazine of Natural History, Zoology, Botany, and Geology 4th Ser., Vol. 6, 34-43.

Laubichler, M.: 2000, Homology in Development and the Development of the Homology Concept, American Zoologist 40, 777-788.

Lauder, G.V.: 1990, 'Functional morphology: Studying functional patterns in an historical context', Annual Review of Ecology and Systematics 21, 317-40.

Lauder, G.V.: 1994, Homology, Form, and Function, in B.K. Hall (ed.), Homology: The Hierarchical Basis of Comparative Biology, Academic Press, San Diego, pp. 151-196.

Le Guyader, H.: 2004, Etienne Geoffroy Saint-Hilaire, 1772-1844: A Visionary Naturalist, 
University of Chicago Press, Chicago.

Love, A.C.: 2001, 'Evolutionary Morphology, Innovation, and the Synthesis of Evolution and Development', Biology and Philosophy 18(2), 309-345.

Love, A.C. and R.A. Raff: 2003, 'Knowing your ancestors: themes in the history of evo-devo', Evolution \& Development 5(4), 327.

Love, A.C. and Raff, R.A.: 2006, Larval Ectoderm, Organizational Homology, and the Origins of Evolutionary Novelty, Journal of Experimental Zoology (Molecular and Developmental Evolution) 306B, 18-34.

Maienschein, J. and M.D. Laubichler: 2007, From Embryology to Evo-Devo: A History of Developmental Evolution. MIT Press, Cambridge, MA.

Matthen, M.: 1998, Biological Universals and the Nature of Fear, The Journal of Philosophy $95,105-132$.

Matthen, M.: 2000, What is a Hand? What is a Mind? Revue Internationale de Philosophie 214, 653-672.

Mayr, E.: 1960, 'The emergence of evolutionary novelties', Evolution After Darwin, 1. University of Chicago Press, Chicago, pp. 349-380.

Millikan, R.G.: 1984, Language, Thought \& Other Biological Categories. MIT Press, Cambridge, MA.

Müller, G.B.: 2003, Homology: The Evolution of Morphological Organization, in G.B. Müller and S.A. Newman (eds.), Origination of Organismal Form: Beyond the Gene in Developmental and Evolutionary Biology, MIT Press, Cambridge, MA, pp. 52-69.

Müller, G.B. and Newman, S.A.: 1999, Generation, Integration, Autonomy: Three Steps in the Evolution of Homology, in G.R. Bock and G. Cardew (eds.), Homology, John Wiley \& Sons, Chicester, pp. 65-73.

Müller, G.B. and S. Newman (eds.): 2003, Origination of Organismal Form: Beyond the Gene in Developmental and Evolutionary Biology. MIT Press, Cambridge, MA.

Müller, G.B. and G.P. Wagner: 1991, 'Novelty in evolution: restructuring the concept', Annual Review of Ecology and Systematics 22, 229-256. 
Müller, G.B. and Wagner, G.P.: 1996, Homology, Hox Genes, and Developmental Integration, American Zoologist 36, 4-13.

Newman, S,A, and Müller, G.B.: 2000, Epigenetic Mechanisms of Character Origination, Journal of Experimental Zoology (Molecular and Developmental Evolution) 288, 304317.

Nyhart, L.: 1995. Biology Takes Form: Animal Morphology and the German Universities, 1800-1900, University of Chicago Press, Chicago.

Owen, R.: 1843, Lectures on the Comparative Anatomy and Physiology of the Invertebrate Animals, Delivered at the Royal College of Surgeons in 1843, Longman, Brown, Green, and Longmans, London.

Owen, R.: 1848, On the Archetype and Homologies of the Vertebrate Skeleton, John van Voorst, London.

Putnam, H.: 1967, 'The Nature of Mental States', in W.G. Lycan (ed.), Mind and Cognition: a Reader. Blackwell, Oxford, pp. 47-56.

Quiring, R., U. Walldorf, U.G. Kloter, and W.J. Gehring: 1994, 'Homology of the eyeless gene of Drosophila to the small eye gene in mice and Aniridia in humans', Science 265, 785-89.

Remane, A.: 1956, Die Grundlagen des natürlichen Systems, der vergleichenden Anatomie und der Phylogenetik, 2nd edition, Geest und Portig, Leipzig.

Rieppel, O.: 2006, Modules, Kinds, and Homology. Journal of Experimental Zoology (Molecular and Developmental Evolution) 304B, 18-27.

Russell, E.S.: 1916, Form and Function: A Contribution to the History of Animal Morphology, J. Murray, London.

Shubin, N., C. Tabin and S. Carroll: 1997, 'Fossils, genes and the evolution of animal limbs', Nature 388(6643), 639-648.

Sober, E.: 1985, 'Putting the Function Back into Functionalism', in W.G. Lycan (ed.), Mind and Cognition: a Reader. Blackwell, Oxford, pp. 97-106.

Sober, E.: 1988, Reconstructing the Past: Parsimony, Evolution and Inference, Cambridge, 
MA: MIT Press.

Wilson, R.A. (ed.) 1999, Species: New Interdisciplinary Essays. MIT Press, Cambridge, MA. Wagner, G.P.: 1989a, The Biological Homology Concept, Annual Review of Ecology and Systematics 20, 51-69.

Wagner, G.P.: 1989b, The Origin of Morphological Characters and the Biological Basis of Homology, Evolution 43, 1157-1171.

Wagner, G.P.: 1994, Homology and the Mechanisms of Development, in B.K. Hall (ed.), Homology: The Hierarchical Basis of Comparative Biology, Academic Press, San Diego, pp. $273-299$.

Wagner, G.P.: 1996, Homologues, Natural Kinds and the Evolution of Modularity, American Zoologist 36, 36-43.

Wagner, G.P.: 2000, What Is the Promise of Developmental Evolution? Part I: Why Is Developmental Biology Necessary to Explain Evolutionary Innovations? Journal of Experimental Zoology (Molecular and Developmental Evolution) 288, 95-98.

Wagner, G.P.: 2001a, Characters, Units and Natural Kinds: An Introduction, in G.P. Wagner (ed.), The Character Concept in Evolutionary Biology, Academic Press, San Diego, pp. $1-10$.

Wagner, G.P. (ed.): 2001b, The Character Concept in Evolutionary Biology, Academic Press, San Diego.

Wagner, G.P.: 2007, The Developmental Genetics of Homology, Nature Review Genetics 8, 473-479.

Wagner, G.P. and Stadler, P.F.: 2003, Quasi-Independence, Homology and the Unity of Type: A Topological Theory of Characters, Journal of Theoretical Biology 220, 505-527.

Wilson, R.A., Barker, M.J., and Brigandt, I.: in press, When Traditional Essentialism Fails: Biological Natural Kinds, Philosophical Topics.

Wouters, A.: 2003, 'Four notions of biological function', Studies in History \& Philosophy of Biological and Biomedical Sciences 34, 633-668.

Wouters, A.: 2005, 'The Functions Debate in Philosophy', Acta Biotheoretica 53, 123-151. 